\title{
Enzymic $\boldsymbol{N}$-Acetylation of $\boldsymbol{N}$-Hydroxy-2-aminofluorene by Liver Gytosol from Various Species
}

\author{
By Prabhakar D. Lotlikar and Leida LuHa \\ Fels Research Institute and the Department of Biochemistry, \\ Temple University School of Medicine, Philadelphia, Pa. 19140, U.S.A.
}

(Received 6 April 1971)

Many mammalian species metabolize various drugs and carcinogenic aromatic amines via acetylation (Williams, 1967). Since the discovery of $N$-hydroxylation of AAF* in the rat (Cramer, Miller \& Miller, 1960), it has been shown unequivocally that $N$-hydroxylation is the first step of activation in carcinogenesis by aromatic amines and amides (Miller, 1970). Like $N$-hydroxy-AAF, its deacetylated synthetic derivative $N$-hydroxy-2-aminofluorene is also more carcinogenic than the parent amide (Miller, 1970). It has been shown that $N$ hydroxy-AAF is readily deacetylated by liver and other tissue preparations from several mammalian species (Irving, 1966; Grantham, Weisburger \& Weisburger, 1965). Administration of $N$-hydroxy-2aminofluorene to rats resulted in the urinary excretion of various acetylated metabolites including $N$-hydroxy-AAF, which was excreted as the glucuronide (Miller, Cooke, Lotlikar \& Miller, 1964; Weisburger, Grantham \& Weisburger, 1966). On the basis of urinary-excretion patterns in the rats, Weisburger et al. (1966) suggested that the formation of $N$-hydroxy-AAF was achieved in vivo by direct $N$-acetylation of $N$-hydroxy-2aminofluorene.

There is no report in the literature that would indicate that $N$-hydroxy amines are acetylated directly. The present study was therefore undertaken to test whether $N$-hydroxy-2-aminofluorene could be directly $N$-acetylated to form $N$-hydroxyAAF by liver cytosol from rat and other species in presence of acetyl-CoA.

$N$-Hydroxy-AAF and $N$-hydroxy-2-aminofluorene were prepared as described by Poirier, Miller \& Miller (1963) and Lotlikar, Miller, Miller \& Margreth (1965) respectively. 2-Aminofluorene and AAF were purchased from $\mathrm{K} \& \mathrm{~K}$ Laboratories, Plainview, N.Y., U.S.A., and Mann Research Laboratories, New York, N.Y., U.S.A., respectively. Unlabelled acetyl-CoA as the lithium salt was a product of P-L Biochemicals Inc., Milwaukee, Wis., U.S.A., and $\left[1-{ }^{14} \mathrm{C}\right]$ acetyl-CoA (sp. radioactivity $58.1 \mathrm{mCi} / \mathrm{mmol}$ ) was bought from New England Nuclear Corp., Boston, Mass., U.S.A. All other chemicals were of reagent grade.

The body weights of adult male animals used in this study were as follows: Sprague-Dawley-strain

* Abbreviation: AAF, 2-acetamidofluorene. rats, 200-250g; Syrian golden hamsters, $100-110 \mathrm{~g}$; Swiss mice, 20-25g; and New Zealand rabbits, 1100-1300g. All animals were fed on commercial diets. All animals except rabbits were decapitated; the rabbits were killed by air embolism. The livers were immediately removed and chilled in ice-cold $0.25 \mathrm{M}$-sucrose. A $20 \%(\mathrm{w} / \mathrm{v})$ liver homogenate prepared in $0.2 \mathrm{M}$-tris-HCl buffer, $\mathrm{pH} 8.0$, was centrifuged at $105000 \mathrm{~g}$ for $60 \mathrm{~min}$. The supernatant was used for enzyme assay.

The incubation medium contained $100 \mu \mathrm{mol}$ of tris-HCl buffer, $\mathrm{pH} 8.0,4 \mu \mathrm{mol}$ of substrate dissolved in $0.1 \mathrm{ml}$ of dimethyl sulphoxide, $1 \mu \mathrm{mol}$ of acetyl-CoA containing $\left[1-{ }^{14} \mathrm{C}\right]$ acetyl-CoA $(5 \times$ $10^{5}$ d.p.m.), liver cytosol equivalent to $100 \mathrm{mg}$ wet wt. of liver and water to a final volume of $1.0 \mathrm{ml}$. After incubation of duplicate samples in air for $30 \mathrm{~min}$ at $37^{\circ} \mathrm{C}, 2.5 \mathrm{ml}$ of $0.5 \mathrm{M}$-hydrochloric acid was added to each tube and the contents were extracted with $10 \mathrm{ml}$ of benzene. The benzene extract was washed several times with water and then extracted with $0.5 \mathrm{M}$-sodium hydroxide. The alkali extract, after several washings with benzene, was neutralized to $\mathrm{pH} 6.0$ with acetic acid and was re-extracted with benzene. Radioactivity in samples of washed benzene extracts containing alkali-soluble or neutral fluorene derivatives was measured in a Packard Tri-Carb spectrometer, in $10 \mathrm{ml}$ of Bray's (1960) solution. In some cases, benzene extracts containing alkali-soluble or neutral fluorene derivatives were chromatographed on Whatman no. 1 paper with the solvent system of Weisburger, Weisburger, Morris \& Sober (1956), composed of cyclohexane-2-methylpropan - 2-ol-acetic acidwater (16:4:2:1, by vol.). After chromatography the strips were air-dried and then viewed under u.v. light. Appropriate u.v.-absorption zones of the authentic 1-, 3-, 5-, 7- and N-hydroxy-AAF and AAF were recorded and, accordingly, corresponding zones were cut out, put into scintillation vials and eluted in $1 \mathrm{ml}$ of methanol for $30 \mathrm{~min} ; 10 \mathrm{ml}$ of Bray's (1960) solution was added to each vial for radioactivity measurements. A Coleman-Hitachi model 124 spectrophotometer with a recorder was used for determination of the u.v.-absorption spectra between 350 and $270 \mathrm{~nm}$.

Our studies with 2-aminofluorene indicate that the acetylase enzyme system present in rat liver 
Table 1. Enzymic N-acetylation of N-hydroxy-2-aminofuorene and 2-aminofluorene by liver cytosol from various species

Adult male animals were used in this study. The liver supernatant obtained after centrifugation at $105000 \mathrm{~g}$ for $60 \mathrm{~min}$ was used for enzyme assay. Tissue from one animal was used for each analysis except with mice where livers from three or four animals were used for each analysis. Incubation medium and all other details are described in the text. The amounts formed were measured as radioactivity in the benzene extract. Results are given as means \pm S.w.M.

Amount formed (nmol/30 min per $100 \mathrm{mg}$ wet wt. of liver)

$\begin{array}{lc}\text { Species } & \begin{array}{c}\text { No. of } \\ \text { analyses }\end{array} \\ \text { Rat } & 5 \\ & 4 \\ \text { Hamster } & 6 \\ & 2 \\ \text { Mouse } & 4 \\ & 2 \\ \text { Rabbit } & 3 \\ & 4 \\ & 5\end{array}$

Substrate

2-Aminofluorene or $N$-hydroxy-2-aminofluorene

2-Aminofluorene

$N$-Hydroxy-2-aminofluorene

2-Aminofluorene

$N$-Hydroxy-2-aminofluorene

2-Aminofluorene

$N$-Hydroxy-2-aminofluorene

2-Aminofluorene

$N$-Hydroxy-2-sminofluorene

$\begin{array}{cc}\begin{array}{c}\text { Neutral } \\ \text { (AAF) }\end{array} & \begin{array}{c}\text { Alkali-soluble } \\ (N \text {-hydroxy-AAF })\end{array} \\ 0.30 \pm 0.09 & 0.08 \pm 0.03 \\ 462 \pm 26 & 0.32 \pm 0.03 \\ 103 \pm 66 & 1.78 \pm 0.77 \\ 1165 \pm 25 & 1.1 \pm 0.4 \\ 507 \pm 101^{*} & 7.4 \pm 1.7^{*} \\ 826 \pm 26 & 1.24 \pm 0.06 \\ 71 \pm 4.5 & 0.65 \pm 0.09 \\ 998 \pm 67 & 0.7 \pm 0.23 \\ 212 \pm 90 & 31 \pm 11.1^{*}\end{array}$

* Statistical comparisons with $N$-hydroxy-2-aminofluorene as the substrate made between rat and other species; $P$ values $<0.001$ are considered highly significant.

cytosol shows optimum activity at about pH8 (P. D. Lotlikar \& L. Luha, unpublished work). In the present experiments, therefore, acetylation was investigated at pH 8.0 (Table 1). In the absence of enzyme, neither of the two substrates was acetylated by acetyl-CoA. With liver cytosol preparation from every species tested, it was found that the total amount of acetylation was severalfold more with 2-aminofluorene than that with its $N$-hydroxy derivative. Acetylation of 2-aminofluorene by liver enzyme gave only one product, which was insoluble in acid or alkali. In ethanol, it showed a u.v.-absorption spectrum that was almost similar to that of the synthetic AAF. However, enzymic acetylation of $N$-hydroxy-2-aminofluorene gave two products. A large percentage of the reaction products was alkali-insoluble material, which was characterized as AAF. The second product was acidic and hence alkali-soluble. The radioactivity pattern after paper chromatography of the benzene extract containing alkali-soluble radioactive material revealed that all of the radioactivity was located in the region where synthetic $N$-hydroxyAAF had travelled. Moreover, with rabbit liver cytosol, the u.v.-absorption spectrum in ethanol of the alkali-soluble product was similar to that of the synthetic $N$-hydroxy-AAF.

In the present studies, the formation of AAF with $N$-hydroxy-2-aminofluorene as the substrate was most probably due to the enzymic reduction of $N$-hydroxy-2-aminofluorene to 2-aminofluorene (Lotlikar et al. 1965; Kiese \& Wiedemann, 1968) and subsequent acetylation of 2 -aminofluorene
(Peters \& Gutmann, 1955; the present paper). Enzymic reduction of $N$-hydroxy-AAF could also give rise to AAF (Lotlikar et al. 1965; Grantham et al. 1965).

Irving (1970) suggested that the formation of $N$-hydroxy-AAF from $N$-hydroxy-2-aminofluorene in studies in vivo (Miller et al. 1964; Weisburger et al. 1966) could be accounted for by several metabolic steps that have been shown to occur in studies in vitro: (1) reduction of $N$-hydroxy-2-aminofluorene to 2-aminofluorene (Lotlikar et al. 1965; Kiese \& Wiedemann, 1968); (2) acetylation of 2aminofluorene to AAF (Peters \& Gutmann, 1955; the present paper); (3) $N$-hydroxylation of AAF to $N$-hydroxy-AAF by liver microsomal fraction in the presence of NADPH and $\mathrm{O}_{2}$ (Irving, 1964 ; Lotlikar, Enomoto, Miller \& Miller, 1967). In the present experiments, $N$-hydroxy-AAF was formed from $N$. hydroxy-2-aminofluorene with liver cytosol preparations from all four species tested. The rabbit liver was severalfold more active than the liver from other animals. In our studies the formation of the $N$-hydroxy compound via $N$-hydroxylation of AAF could be ruled out, because a cytosol preparation devoid of microsomal fraction was employed. If our cytosol preparations had been contaminated with some microsomal fraction, even then formation of $N$-hydroxy-AAF was negligible with 2aminofluorene rather than $N$-hydroxy-2-aminofluorene as the substrate. The present results could be accounted for only on the basis of direct $\mathrm{N}$-acetylation of $\mathrm{N}$-hydroxy-2-aminofluorene to form $N$-hydroxy-AAF. These results suggest that 
$N$-hydroxy-AAF could arise in vivo by direct $N$ acetylation of $N$-hydroxy-2-aminofluorene. It is possible that both direct and indirect pathways are operative in vivo. However, it is not possible at the present time to indicate the amount of acetylation contributed by either pathway in vivo. The present report is the first example of direct $N$-acetylation of a $N$-hydroxy compound.

This investigation was supported by a grant (CA-10604) and a Career Development Award (5-K04-CA-42362) from the National Cancer Institute, U.S. Public Health Service.

Bray, G. A. (1960). Analyt. Biochem. 1, 279.

Cramer, J. W., Miller, J. A. \& Miller, E. C. (1960). J. biol. Chem. 235, 885.

Grantham, P. H., Weisburger, E. K. \& Weisburger, J. H. (1965). Biochim. biophys. Acta, 107, 414.

Irving, C. C. (1964). J. biol. Chem. 239, 1589.

Irving, C. C. (1966). Cancer Res. 26, 1390.
Irving, C. C. (1970). In Metabolic Conjugation and Metabolic Hydrolysis, vol. 1, p. 53. Ed. by Fishman, W. H. New York and London: Academic Press.

Kiese, M. \& Wiedemann, I. (1968). Biochem. Pharmac. $17,1151$.

Lotlikar, P. D., Enomoto, M., Miller, J. A. \& Miller, E. C. (1967). Proc.Soc.exp. Biol.Med.125,341.

Lotlikar, P. D., Miller, E. C., Miller, J. A. \& Margreth, A. (1965). Cancer Res. 25, 1743.

Miller, E. C., Cooke, C. W., Lotlikar, P. D. \& Miller, J. A. (1964). Proc. Am. Ass. Cancer Res. 5, 45.

Miller, J. A. (1970). Cancer Res. 30, 559.

Peters, J. H. \& Gutmann, H. R. (1955). J. biol. Chem. 216, 713.

Poirier, L. A., Miller, J. A. \& Miller, E. C. (1963). Cancer Res. 23, 790 .

Weisburger, J. H., Grantham, P. H. \& Weisburger, E. K. (1966). Biochem. Pharmac. 15, 833.

Weisburger, J. H., Weisburger, E. K., Morris, H. P. \& Sober, H. A. (1956). J. natn. Cancer Inst. 17, 363.

Williams, R. T. (1967). In Biogenesis of Natural Compounds, p. 589. Ed. by Bernfeld, P. Oxford and New York: Pergamon Press. 